\title{
Effects of air pollution and climatic conditions on the frequency of ophthalmological emergency examinations
}

\section{T Bourcier, C Viboud, J-C Cohen, F Thomas, T Bury, L Cadiot, O Mestre, A Flahault, V Borderie, L Laroche}

\section{Research is needed on the association between weather and air pollutants}

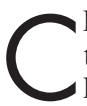
lear recognition of the implications of outdoor air pollution on health is a relatively recent development. Numerous epidemiological studies have demonstrated short term associations between high levels of air pollution and increased acute mortality and morbidity. ${ }^{1-6}$ Relations between asthma, bronchitis, cardiovascular conditions (that is, coronary disease), headaches, and outdoor pollution rates have so far been described. ${ }^{7-9}$ In the recent years, the variety and rates of pollutants in the atmosphere have appeared to be on the increase. ${ }^{7}$ The increase has been caused by the general rise in vehicle traffic. Short term meteorological conditions such as air temperature, humidity, and atmospheric pressure have also been shown to influence the pollution rates.

The aim of the study was (1) to investigate short term association between the number of ophthalmological emergencies, urban air pollution, and climatic conditions in Paris; (2) to determine the possibility of creating a surveillance system capable of monitoring trends in the relation between air pollution and ophthalmological emergencies.

Data collected were the daily number of examinations in the ophthalmological emergency department of the QuinzeVingts National Centre of Ophthalmology, Paris, from l January 1999 to 31 December 1999. In addition to the overall daily number of examinations, one tenth of the daily clinical diagnoses were randomly selected, computerised, and classified into three categories consisting of medical emergencies, ocular traumas and surgical emergencies, conjunctivitis and related ocular surface problems. We included in the latter category discomfort eye syndrome, which includes a series of minor subjective symptoms (heaviness of the lids, foreign body sensation, burning, stinging, photophobia) in patients where no relevant clinical signs are observed..$^{10}$ Medical emergencies, as well as trauma and surgical emergencies, were used as "control diagnoses," for which we did not expect to find any association with environmental factors.

The pollutants measured in this study were provided by the Paris air pollution network, AIRPARIF. Five major urban air pollutants were examined: nitrogen oxide $(\mathrm{NO})$, nitrogen dioxide $\left(\mathrm{NO}_{2}\right)$, ozone $\left(\mathrm{O}_{3}\right)$, sulphur dioxide $\left(\mathrm{SO}_{2}\right)$, particles with a median aerodynamic diameter of $<10 \mu \mathrm{m}$ (PM10). Meteorological data for the Paris area were provided by the national weather service, MeteoFrance. These data consisted of the daily minimum and maximum temperature, the daily minimum and maximum humidity, the mean daily atmospheric pressure, wind speed and strength.

We considered two separate types of models for analysing ophthalmological and environmental data. We first used the series of the daily number of conjunctivitis and related ocular surface problems and built a logistic regression model with the ratio of this number to the daily total number of randomised diagnoses as the dependent variable. Pollution and meteorological covariates, as well as the dummy indicators detailed above, were included in a stepwise procedure which allowed for selecting the "best model." We studied various lags $(0,1,2$, and 3 days $)$ for the covariates to account for a potential delay between the exposure and the effect on the eye. Then, we designed a model to predict the occurrence of peak numbers of examinations. For each category of diagnoses and for the total number of examinations in the emergency department, the series were categorised into peak days (when

Table 1 Air pollution, weather, and ophthalmological data, Paris, January 1999 to December 1999 (n=361 days, excluding the 4 day solar eclipse period 9-12 August)

\begin{tabular}{|c|c|c|c|}
\hline & Min & Max & Mean \\
\hline \multicolumn{4}{|l|}{ Ophthalmological data: } \\
\hline All diagnoses $\dagger$ & 47 & 125 & 83.4 \\
\hline Randomised diagnoses $\ddagger$ & 5 & 13 & 8.3 \\
\hline Conjunctivitis and other related ocular surface problems, No (\%*) & $0(0)$ & $9(100)$ & $3.4(42)$ \\
\hline Medical emergencies, № $\left(\%^{*}\right)$ & $0(0)$ & $7(88)$ & $2.8(33)$ \\
\hline Traumatic and surgical emergencies, No $\left(\%^{*}\right)$ & $0(0)$ & $6(67)$ & $2.1(25)$ \\
\hline \multicolumn{4}{|l|}{ Pollution data: } \\
\hline $\mathrm{NO}\left(\mu \mathrm{g} / \mathrm{m}^{3}\right)$ & 3 & 238 & 22.4 \\
\hline $\mathrm{NO}_{2}\left(\mu \mathrm{g} / \mathrm{m}^{3}\right)$ & 19 & 115 & 53.7 \\
\hline $\mathrm{O}_{3}\left(\mu \mathrm{g} / \mathrm{m}^{3}\right)$ & 1 & 97 & 35.7 \\
\hline $\mathrm{SO}_{2}\left(\mu \mathrm{g} / \mathrm{m}^{3}\right)$ & 2 & 45 & 11.2 \\
\hline PM10 $\left(\mathrm{\mu g} / \mathrm{m}^{3}\right)$ & 58 & 711 & 218.3 \\
\hline \multicolumn{4}{|l|}{ Weather data: } \\
\hline Temperature $\left({ }^{\circ} \mathrm{C} \mathrm{min}\right.$ ) & -3.1 & 20.7 & 9.31 \\
\hline Temperature $\left({ }^{\circ} \mathrm{C}\right.$ max $)$ & 2 & 33 & 16.9 \\
\hline Atmospheric pressure $(\mathrm{hPa})$ & 979.2 & 1030.5 & 1007 \\
\hline Humidity (\% min) & 18 & 92 & 54.7 \\
\hline Humidity ( $\%$ max) & 64 & 98 & 89.9 \\
\hline Average wind speed $(\mathrm{m} / \mathrm{s})$ & 1 & 7.3 & 3.1 \\
\hline Instant wind strength $(\mathrm{m} / \mathrm{s})$ & 5 & 47 & 11.4 \\
\hline
\end{tabular}

* In proportion of all randomised diagnoses.

†30 883 patients were examined during the study period.

$\ddagger 3042$ diagnoses were randomised. 
Table 2 Relative risks estimates of conjunctivitis for an increase from the 5 th to the 95 th percentile of a pollution variable adjusted on the day of the week. The univariate model is adjusted on the day of the week. The multivariate model includes all environmental covariates and the day of the week, the most significant of which are selected by a stepwise procedure

\begin{tabular}{|c|c|c|c|c|c|c|}
\hline & $\begin{array}{l}\text { Lag } \\
\text { (days) }\end{array}$ & $\begin{array}{l}\text { Univariate RR* } \\
\text { P95/P5 }\end{array}$ & $95 \% \mathrm{Cl}+$ & $\begin{array}{l}\text { Multivariate RR } \\
\text { P95/P55 }\end{array}$ & $95 \% \mathrm{Cl}$ & Range P95/P5 \\
\hline NO & 2 & $1.11, p=0.28$ & 0.92 to 1.36 & & & $80 / 3$ \\
\hline $\mathrm{NO}_{2}$ & 2 & $1.27, p=0.04$ & 1.01 to 1.60 & $1.51, p=0.002$ & 1.17 to 1.96 & $80 / 30$ \\
\hline $\mathrm{O}_{3}$ & 0 & $1.13, p=0.28$ & 0.90 to 1.42 & & & $74 / 5$ \\
\hline $\mathrm{SO}_{2}$ & 1 & $0.88, p=0.31$ & 0.70 to 1.12 & & & $27 / 2$ \\
\hline PMIO & 2 & $1.20, p=0.11$ & 0.96 to 1.49 & & & $388 / 101$ \\
\hline Temperature (min) & 1 & $0.94, p=0.57$ & 0.77 to 1.15 & & & $0.7 / 17.6$ \\
\hline Temperature (max) & 3 & $0.95, p=0.58$ & 0.78 to 1.15 & $1.29, p=0.007$ & 1.07 to 1.56 & $5.3 / 29.8$ \\
\hline Atmospheric pressure & 2 & $1.11, p=0.35$ & 0.90 to 1.36 & & & 1019.6/991.2 \\
\hline Humidity (min) & 3 & $1.13, p=0.20$ & 0.94 to 1.35 & & & $82 / 33$ \\
\hline Humidity (max) & 2 & $0.84, p=0.13$ & 0.66 to 1.06 & & & $77 / 97$ \\
\hline Average wind speed & 0 & $1.10, p=0.28$ & 0.92 to 1.31 & & & $5.0 / 1.6$ \\
\hline Instant wind strength & 0 & $1.12, p=0.15$ & 0.96 to 1.31 & $1.17, p=0.03$ & 1.02 to 1.36 & $19 / 6$ \\
\hline
\end{tabular}

the value of the series for that day was above the 75 th percentile of the distribution) and normal days (when it was below). Logistic regression models were used to predict the occurrence of peaks, including the environmental parameters and a dummy indicator for each day of the week as covariates. Separately for each of the four series considered, the "best model" was built by a stepwise procedure which retained the covariates that were the most appropriate to explain the observed peaks.

A total of 30883 patients were examined in the emergency department of the Quinze-Vingts National Centre of Ophthalmology during year 1999 and 3042 diagnoses were recorded in the randomisation process. Among these, 41.8\% were categorised as conjunctivitis and related ocular surface problems, $25.0 \%$ as trauma or surgical emergencies, and $33.3 \%$ as medical emergencies. Summary statistics for the study are presented in Table 1.

The relation between conjunctivitis and related ocular surface problems, air pollution, and meteorological parameters was strong. The oxidative environmental pollutant $\mathrm{NO}_{2}$, as well as the maximum temperature of the day and instant wind strength, were associated with conjunctivitis and other ocular surface diseases (Table 2). The medical emergencies were associated with the day of the week only $(p<0.001)$ and the trauma or surgical emergencies were not associated with any of the covariates tested. Hence, no association between environmental factors and our "control diagnoses" was retrieved at the 5\% level.

Of the 361 days of the study period, excluding the eclipse period, 276 days $(76.4 \%)$ were considered as normal days for the total number of visits to the emergency department (less than 92 patients were seen), and $85(23.5 \%)$ were considered as peak days. The selection procedure of the logistic model retained several environmental variables: $\mathrm{NO}$, $\mathrm{NO}_{2}$, atmospheric pressure, minimum humidity, and average wind speed. The sensitivity was $48.2 \%$ and the specificity was $93.4 \%$, corresponding to a positive predictive value of $69.5 \%$ and a negative predictive value of $85.4 \%$. As regards specific diagnoses-namely, conjunctivitis and related ocular surface problems, medical emergencies, trauma, and surgical emergencies, the selected models were not appropriate to predict the occurrence of peaks, and the resulting sensitivity was less than $2 \%$.

A survey of the literature shows that very little information is available regarding the effects of air pollution on the eye compared to the pulmonary system. Some of these data come from experimental studies in which pollutants were used on human volunteers or animals in arbitrary doses or even in higher than those ever expected during episodes of air pollution. ${ }^{11}{ }^{12}$ Concerning the direct effect of air pollution on the eye, most of the studies dealt with the conditions of the ocular surface, and used eye irritation as the criterion for the effects of the air pollutants. ${ }^{13}$ Manifestations can range from minimal or no symptoms to chronic discomfort and eye irritation, ${ }^{11}{ }^{14}$ reduction of visibility, and increased light sensitivity. ${ }^{15}$ There may also be specific situations, for contact lens wearers, for example, where the eyes may be adversely affected by air pollution. ${ }^{16}$

This study suggests that high levels of air pollution experienced in Paris are linked to short term increases in the number of people visiting ophthalmological emergency department. The present results are in agreement with those of other short term epidemiological studies concerning health problems. Significant correlations between visits for asthma and $\mathrm{SO}_{2}, \mathrm{NO}_{2}$, and PMlO has been demonstrated. ${ }^{17}$ Moreover, the association between carbon monoxide (CO), $\mathrm{NO}_{2}$ and coronary events, hospitalisations and mortality, has been shown in a large epidemiological study. ${ }^{7}$ However, our results indicate a strong relation between air $\mathrm{NO}, \mathrm{NO}_{2}$ concentrations, and conjunctivitis. NO is released in the atmosphere from vehicles, which are the main sources of atmospheric NO. ${ }^{18} \mathrm{NO}$ and $\mathrm{NO}_{2}$ are primary pollutants which undergo various complex atmospheric reactions to generate secondary pollutants (that is, $\mathrm{O}_{3}$ ) which are known to cause severe adverse effects on human health. The typical sequence in the development of oxidant pollution is an initial increase in nitrous oxide, followed by nitrogen dioxide, followed by ozone. These pollutants can be carried long distances and may have long range effects. Nitrogen dioxide is known as a deep lung irritant. ${ }^{17}$ Changes in the lacrimal $\mathrm{pH}$, such as those produced by acidification of tears in an atmosphere with a high oxidant power $\left(\mathrm{NO}, \mathrm{NO}_{2}, \mathrm{SO}_{2}\right)$, could thus exert irritant effect on the ocular surface. ${ }^{19}$ Furthermore, we find that atmospheric pressure, minimal humidity, and wind speed may have direct mechanical or biological effects on the ocular surface and could thus increase the incidence of ocular surface complaints. We could thus hypothesise that the ophthalmic effects of air pollutants and allergenic pollens can be enhanced by hot weather conditions. On the other hand, other parameters such as low humidity, and wind strength may directly affect tear film stability.

In this study, we were able to use environmental data as predictors for the occurrence of the peak number of visits to an ophthalmological emergency department, and predicted more than half of the observed peaks, with high specificity (93\%). The next step would be to try to establish an operational early warning system within the hospital to issue forecasts of the incoming number of patients, 
one or several days in advance. However, we were not able to predict the occurrence of peaks in the number of conjunctivitis and related ocular surface problems. This might be due to the small number of diagnoses randomised each day (around eight), from which the number of cases of conjunctivitis is derived. Indeed, in some of the "peak days" defined by our algorithm (using the 75 percentile cut off), the amount of conjunctivitis was not statistically different from that observed on "normal days."

In conclusion, our study suggests that the levels of air pollution experienced in Paris are linked to short term increases in the number of people visiting an ophthalmological emergency department. Prospective research is needed on the association between weather and air pollutants and allergens in order to improve air pollution models and their linkage with climate change scenarios, and closing gaps in the understanding of exposure patterns and ophthalmological effects. Such studies will help to determine the long term effects of air pollutants on the eye, which are currently unknown.

Br J Ophthalmol 2003;87:809-811

Authors' affiliations

T Bourcier, F Thomas, T Bury, L Cadiot,

V Borderie, L Laroche, Quinze-Vingts National

Center of Ophthalmology, Paris, France
C Viboud, OA Flahault, INSERM Unit 444 Saint-Antoine Hospital, Paris, France J-C Cohen, O Mestre, Meteo-France, Paris, France

Correspondence to: Tristan Bourcier, MD, PhD Ophthalmology 5, Quinze-Vingts National Center of Ophthalmology, 28 rue de Charenton 75012 Paris, France; bourcier@quinze-vingts.fr

Accepted for publication 7 January 2003

\section{REFERENCES}

1 Thielebeule U, Pelech L. Epidemiological studies regarding the effects of air pollution. J Hyg Epidemiol Microbiol Immunol 1985;29:353-62

2 Thiele JJ, Podda M, Packer L. Tropospheric ozone: an emerging environmental stress to skin. Biol Chem 1997;378:1299-305.

3 Lippmann M, Ito K, Nadas A, Burnett RT. Association of particulate matter components with daily mortality and morbidity in urban populations. Res Rep Health Eff Inst 2000:5-72, discussion 73-82.

4 Samet JM, Dominici F, Curriero FC, et al. Fine particulate air pollution and mortality in 20 U.S. cities, 1987-1994. N Engl J Med 2000;343: 1742-9

5 Katsouyanni K, Touloumi G, Samoli E, et al. Confounding and effect modification in the short-term effects of ambient particles on total mortality: results from 29 European cities within the APHEA2 project. Epidemiology 2001;12:521-31.

6 Petroeschevsky A, Simpson RW, Thalib L, et al. Associations between outdoor air pollution and hospital admissions in Brisbane, Australia. Arch Environ Health 2001;56:37-52.

7 Medina S, Le Tertre A, Quenel P, et al. Ai pollution and doctors' house calls: results from the ERPURS system for monitoring the effects of air pollution on public health in Greater
Paris, France, 1991-1995. Evaluation des Risques de la Pollution Urbaine pour la Sante Environ Res 1997;75:73-84.

8 Atkinson RW, Anderson HR, Strachan DP, ef al Short-term associations between outdoor air pollution and visits to accident and emergency departments in London for respiratory complaints. Eur Respir J 1999;13:257-65.

9 Atkinson RW, Anderson HR, Sunyer J, et al. Acute effects of particulate air pollution on respiratory admissions: results from APHEA 2 project. Air Pollution and Health: a European Approach. Am J Respir Crit Care Med 2001;164(Pt 1):1860-6.

10 Versura P, Profazio V, Cellini M, et al. Eye discomfort and air pollution. Ophthalmologica 1999:213:103-9.

11 Waheed MA, Basu PK. The effect of air pollutants on the eye. I. The effect of an organic extract on the conjunctival goblet cells. Can J Ophthalmol 1970;5:226-30.

12 Anderson RC, Anderson JH. Sensory irritation and multiple chemical sensitivity. Toxicol Ind Health 1999; 15:339-45.

13 Artridge RA, Stebbings JH Jr, Elsea WR, et al. Outbreak of acute eye irritation associated with air pollution. Public Health Rep 1966;81:153-8.

14 Altshuller AP. Eye irritation as an effect of photochemical air pollution. J Air Pollut Control Assoc 1977;27(1 1): 1 125-6.

15 Basu PK. Air pollution and the eye. Surv Ophthalmol 1972;17:78-93.

16 Klopfer J. Effects of environmental air pollution on the eye. J Am Optom Assoc 1989:60:773-8

17 Schwela D. Air pollution and health in urban areas. Rev Environ Health 2000;15: 13-42.

18 Lal S, Patil RS. Monitoring of atmospheric behaviour of $\mathrm{NOx}$ from vehicular traffic. Environ Monit Assess 2001:68:37-50.

19 Andres S, Garcia ML, Espina M, et al. Tear $\mathrm{pH}$, air pollution, and contact lenses. Am J Optom Physiol Opt 1988;65:627-31.

\section{Video reports}

To view the video reports in full visit our website www. bjophthalmol.com and click on the link to video reports.

- Marin-Amat syndrome. A Jogiya, C Sandy

- Excision of subcutaneous Dirofilariasis of the eyelid. D Mallick, TP Ittyerah

- Thixotropy: a novel explanation for the cause of lagophthalmos after peripheral facial nerve palsy. M Aramideh, J H T M Koelman, P P Devriese, F VanderWerf, J D Speelman

- Surgical revision of leaking filtering blebs with an autologous conjunctival graft. $K$ Taherian, A Azuara-Blanco

- Dipetalonema reconditum in the human eye. T Huynh, J Thean, R Maini

- Evaluation of leucocyte dynamics in mouse retinal circulation with scanning laser ophthalmoscopy. H Xu, A Manivannan, G Daniels, J Liversidge, P F Sharp, J V Forrester, IJ Crane

- An intraocular steroid delivery system for cataract surgery. D F Chang

- Pearls for implanting the Staar toric IOL. D F Chang

- Capsule staining and mature cataracts: a comparison of indocyanine green and trypan blue dyes. D F Chang 